\title{
Special Issue of JSAM Call for Proposals
}

\section{Settler Sounds: Music, Indigeneity, and Colonialism in the Americas}

We are soliciting submissions for a special issue of Journal of the Society for American Music, guest edited by Gabriel Solis (UIUC) and Jessica Bissett Perea (UC Davis), that will investigate sonic aspects of the Americas through a consideration of the distinct, yet related, modes of colonialism and Indigeneity that have come to define the region. The purpose of the issue is twofold: first, to evaluate how a focus on music and other sonic phenomena may help us better understand the sociohistorical formation of the cultures of the Americas; and second, to discover how a focus on modes of discovery, settlement, and expansion of colonial regimes in the Americas and beyond can help us develop transnational perspectives in American music studies. Critically, we hope to use this issue to grapple with the ongoing relevance of Indigenous people and their claims to sovereignty for American music scholarship. In this moment of global upheaval, we ask, how can perspectives that foreground American states' foundational status as settler colonies help bring new relevance to work in our field?

We welcome writing from any discipline of music and American studies, using any methodology. We are particularly interested in studies that take a perspective that crosses linguistic divides-Anglo, Iberian, French, Russian, and more-in American music studies and work that engages beyond the settler-Indigenous dialectic to consider how a settler colonial framework helps understand the sonic dimensions of racialization in the Americas through slavery, immigration, and refugee movement, as well as musical experiences of gender and sexuality.

For questions regarding this special issue, contact Gabriel Solis: gpsolis@illinois.edu

Article submissions should be sent electronically to JSAM's Editor by April 1, 2018. Please indicate in the body of your message that you wish your article to be considered for this special issue:

Prof. Loren Kajikawa

Editor, Journal of the Society for American Music

e-mail: jsameditor@gmail.com

Authors should send their submissions in MS Word and also include an abstract of no more than 200 words. The submission itself should be anonymous throughout the text and notes. Articles should range from 5,000 to 10,000 words (excluding notes). Longer articles will be considered but may be edited for length. 


\section{Cambridge Journals Digital Archive}

Knowledge is no longer shelved
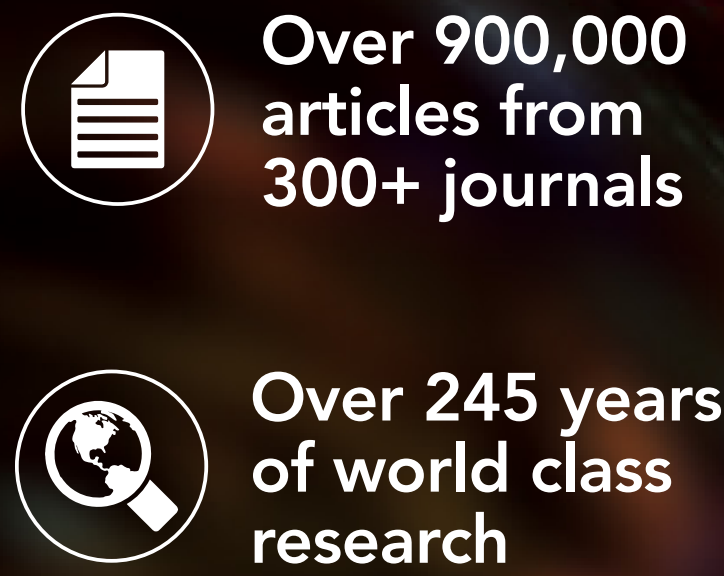

Available in collections, bespoke packages and as individual journal archives

cambridge.org/core-cjda 


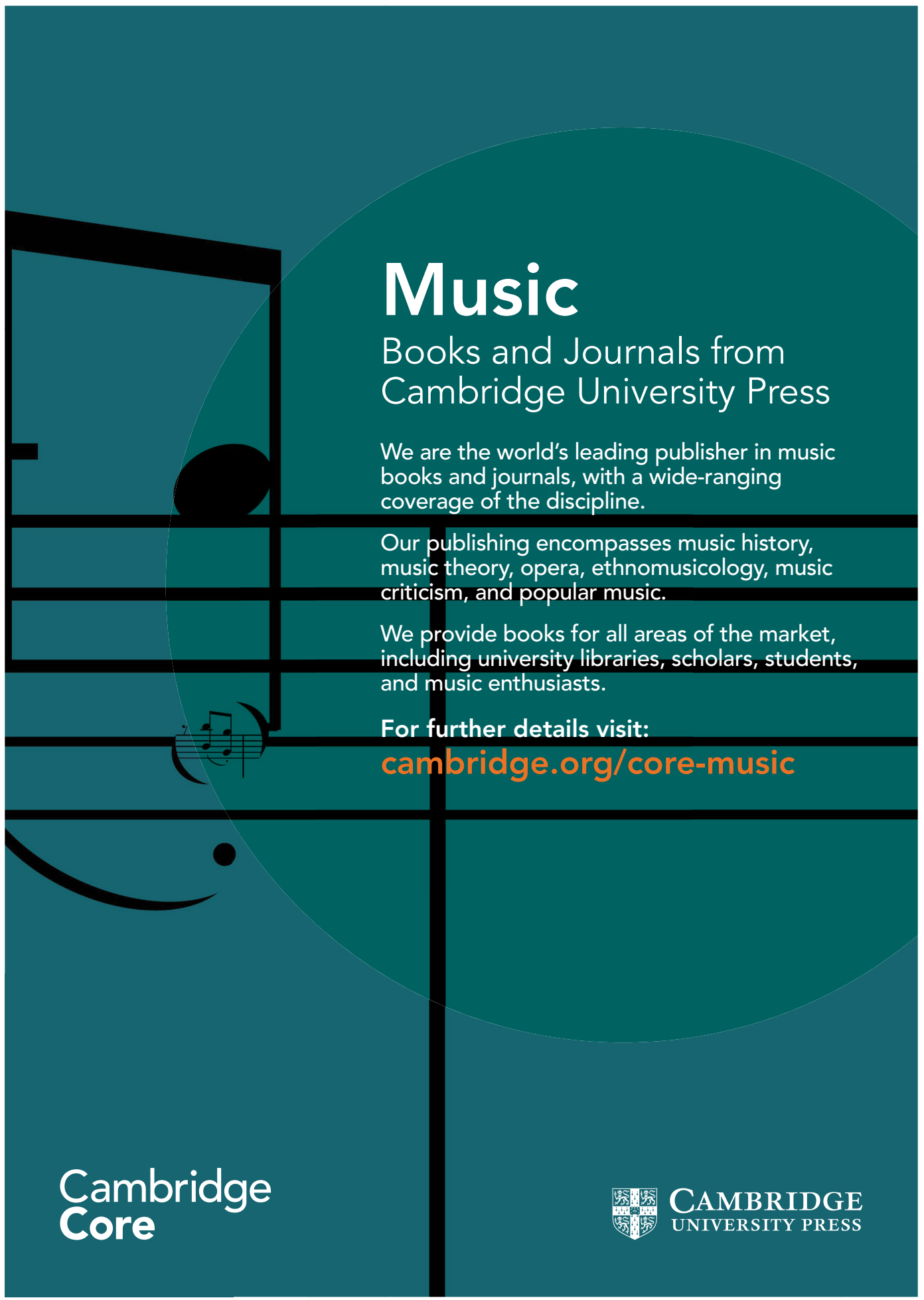




\title{
Journal of the Society for American Music
}

\author{
Instructions for Contributors
}

Article submissions should be sent to:

Prof. Loren Kajikawa

Editor, Journal of the Society for American Music

University of Oregon

e-mail: jsameditor@gmail.com

Authors should submit materials electronically to the e-mail address above. The following documents should be sent: cover letter; abstract of no more than 200 words; article text in MS Word with list of references (.doc); musical examples (.pdf or .jpg); and figures (.jpg). Electronic images should be sent as separate lowresolution jpegs rather than being embedded in the text; ideally each image should be less than $1 \mathrm{MB}$ in size. (If the article is accepted, high resolution tiff or eps images will be required.) Only the cover letter should include the author's name, mailing address, telephone number, and e-mail address. The submission itself should be anonymous throughout the text and notes. Articles should range from 5,000 to 10,000 words (excluding notes). Longer articles will be considered but may be edited for length.

Journal of the Society for American Music employs humanities style for citations, following The Chicago Manual of Style, 17th edition. Use footnotes for explanatory material that need not appear in the main body of the article. At the end of the article, provide a list of references cited. All musical examples, figures, tables, and appendices should be numbered and contain captions, and the text should indicate approximate placement by the use of a callout, e.g., <FIG. 1 ABOUT HERE $>$. Callouts should be placed on a new line after the paragraph in which the figure or example is mentioned. A separate list of captions should be included. Contributors are responsible for obtaining permission to reproduce any material for which they do not hold copyright and for ensuring that the appropriate acknowledgments are included in their typescript. The cost of permissions and reproducing color illustrations will be the responsibility of the author. Upon acceptance of a submission, authors will be asked to assign copyright to the Society for American Music. JSAM does not review articles that are being considered for publication in another journal.

For additional information on preparing submissions, please visit $<$ www.journals.cambridge.org/sam $>$ or $<$ www.american-music.org $>$ to download a current PDF copy of the complete Instructions for Contributors. 
Dominic Symonds, We'll Have Manhattan: The Early Work of Rodgers \& Hart Todd Decker

Phil Jamison, Hoedowns, Reels, and Frolics-Roots and Branches of Southern Appalachian Dance

John Spitzer

Alicia Kopfstein-Penk, Leonard Bernstein and His Young People's Concerts Ann Glazer Niren

\section{Media}

London Sinfonietta and Queen Mary University of London, Steve Reich's

Clapping Music, iPhone ed., v. 1.0.4; Joseph Gender and Third Coast Percussion, Third Coast Percussion: The Music of Steve Reich, iPhone ed., v. 1.0.7

Twila Bakker

James D. Payne, Far West; Haitao Guo, Bright Sun Mansion

Eric Hung

Karen Collins, Beep: A Documentary History of Game Sound; Karen Collins and Chris Greening, Beep: Documenting the History of Game Sound Dana Plank 


\section{JOURNAL OF THE SOCIETY FOR AMERICAN MUSIC}

\section{TABLE OF CONTENTS}

V

CONTRIBUTORS

1 FROM THE EDITOR

\section{Loren Kajikawa}

\section{ARTICLES}

2 Visualizing Music in the Silent Era: The Collaborative Experiments of Visual Symphony

Productions

\section{Mary Simonson}

37 Musical Structure, Dramatic Form, and Song Pairings in Cole Porter's Kiss Me, Kate Michael Buchler

55 The Rise and Fall of "Indie Classical": Tracing a Controversial Term in Twenty-First Century New Music

William Robin

\section{REVIEWS}

\section{BOOKS}

89 Chuck Haddix, Bird: The Life and Times of Charlie Parker; Stanley Crouch, Kansas City Lightning: The Rise and Times of Charlie Parker; Peter Pullman, Wail: The Life of Bud Powell; Guthrie P. Ramsey, Jr., The Amazing Bud Powell: Black Genius, Jazz History, and the Challenge of Bebop

\section{Scott DeVeaux}

